\title{
"EU SOU UMA LÍNGUA": A EXOFONIA NA LITERATURA DE YOKO TAWADA
}

\author{
Gerson Roberto Neumann \\ Marianna Ilgenfritz Daudt
}

Submetido em 07 de maio de 2019.

Aceito para publicação em 13 de julho de 2019.

Cadernos do IL, Porto Alegre, n. ${ }^{\circ}$ 58, outubro. p. 46-59.

\section{POLÍTICA DE DIREITO AUTORAL}

Autores que publicam nesta revista concordam com os seguintes termos:

(a) Os autores mantêm os direitos autorais e concedem à revista o direito de primeira publicação, com o trabalho simultaneamente licenciado sob a Creative Commons Attribution License, permitindo o compartilhamento do trabalho com reconhecimento da autoria do trabalho e publicação inicial nesta revista.

(b) Os autores têm autorização para assumir contratos adicionais separadamente, para distribuição não exclusiva da versão do trabalho publicada nesta revista (ex.: publicar em repositório institucional ou como capítulo de livro), com reconhecimento de autoria e publicação inicial nesta revista.

(c) Os autores têm permissão e são estimulados a publicar e distribuir seu trabalho online (ex.: em repositórios institucionais ou na sua página pessoal) a qualquer ponto antes ou durante o processo editorial, já que isso pode gerar alterações produtivas, bem como aumentar o impacto e a citação do trabalho publicado.

(d) Os autores estão conscientes de que a revista não se responsabiliza pela solicitação ou pelo pagamento de direitos autorais referentes às imagens incorporadas ao artigo. A obtenção de autorização para a publicação de imagens, de autoria do próprio autor do artigo ou de terceiros, é de responsabilidade do autor. Por esta razão, para todos os artigos que contenham imagens, o autor deve ter uma autorização do uso da imagem, sem qualquer ônus financeiro para os Cadernos do IL.

\section{POLÍTICA DE ACESSO LIVRE}

Esta revista oferece acesso livre imediato ao seu conteúdo, seguindo o princípio de que disponibilizar gratuitamente o conhecimento científico ao público proporciona sua democratização. 


\title{
"EU SOU UMA LÍNGUA": A EXOFONIA NA LITERATURA DE YOKO TAWADA
}

\author{
"I AM A TONGUE": \\ THE EXOPHONIC ASPECT IN YOKO TAWADA
}

\author{
Gerson Roberto Neumann* \\ Marianna Ilgenfritz Daudt**
}

\begin{abstract}
RESUMO: A obra da escritora japonesa Yoko Tawada tem recebido crescente destaque e atenção na Alemanha, por se tratar de um caso de escrita exofônica, como ela própria vê a sua produção, e por trazer reflexões pertencentes a múltiplos âmbitos dos Estudos Culturais, como língua, tradução, cultura, pertencimento e nacionalidade. Yoko Tawada é considerada hoje como uma escritora da literatura alemã, mas também é uma escritora japonesa dentro e fora do Japão. Associados a essa forma de produção literária estão conceitos que se movem paralelamente à escrita, ou estão inseridos nela: a língua e a migração.
\end{abstract}

PALAVRAS-CHAVE: Yoko Tawada; literatura alemã; exofonia.

ABSTRACT: Yoko Tawada is a Japanese writer who lives in Germany, where her work is acclaimed as exophonic literature, a concept she helped to coin and which she applies in her writings. Tawada is recognized for raising issues and theoretical discussions that belong to multiple spheres of Cultural Studies, such as language, translation, culture and nationality. Yoko Tawada can be placed today within the realm of German literature and also in Japanese literature both in and outside of Japan. Tawada's type of literary writing is intimately related to the concepts of language and migration.

KEYWORDS: Yoko Tawada; german literature; exophony.

\section{Introdução}

\begin{abstract}
A voz de um autor que vive na migração é, muitas vezes, logo remetida de volta à sua terra natal. Por causa disso, ela é aceita e, ao mesmo tempo, ignorada. $\mathrm{O}$ autor precisa constantemente de novos lugares que não possam ser sua origem e onde ele de maneira alguma precise ser integrado. ${ }^{1}$

(Yoko Tawada)
\end{abstract}

A autora japonesa Yoko Tawada, que aos poucos se torna mais conhecida no cenário literário brasileiro, escreve em língua alemã na Alemanha e também publica em japonês no Japão. No Brasil, país que recebeu muitos imigrantes japoneses, os textos de Tawada podem vir a estabelecer um enriquecedor diálogo não somente com os leitores

\footnotetext{
* Professor Associado de Literatura e Língua Alemã na Universidade Federal do Rio Grande do Sul UFRGS. gerson.neumann@gmail.com

** Mestranda em Literatura Comparada pelo PPG da Letras da Universidade Federal do Rio Grande do Sul.maridaudt@gmail.com

1 Die Stimme eines Autors, der in der Migration lebt, wird oft zu schnell auf sein Herkunftsland zurückgeführt. Dadurch wird sie akzeptiert und gleichzeitig ignoriert. Der Autor braucht stets neue orte, die nicht seine Herkunft sein können und wo er keinesweg integriert werden muss. (Tawada, 2007, p.101). Todas as traduções dos textos de Yoko Tawada apresentados aqui são de tradução nossa.
} 
brasileiros de imigração japonesa como pano de fundo, mas com os diversos grupos imigrantes que formam o povo brasileiro. Com o presente trabalho, pretende-se apresentar a relação da literatura de Yoko Tawada com os fenômenos de alteridade linguística proporcionados por um histórico pessoal de experiência de migração e suas reflexões sobre as ideias correntes de uma produção literária universal delimitada por fronteiras até então fixas. A proposta é realizar uma revisão do conceito de literatura de migração e das controvérsias a respeito de sua adequação como classificação literária, e trazer à discussão o posicionamento da autora em questão, especialmente quando ela trata de temas relacionados ao ato de escrever em uma língua diferente da materna.

Yoko Tawada é uma escritora japonesa que vive há mais de trinta anos na Alemanha e escreve nas duas línguas, japonês e alemão. Nascida em Tóquio no ano de 1960, estudou literatura russa na Universidade de Waseda até se mudar para Hamburgo, aos 22 anos, onde terminou os estudos de Literatura. Desde então produz prosa, poesia, peças de teatro e crítica literária, tanto em sua língua materna, o japonês, quanto na adotada, o alemão. Além de premiada no Japão, Tawada também já recebeu prêmios importantes na Alemanha, em reconhecimento à sua contribuição cultural, por exemplo, o prêmio Adelbert von Chamisso em 1996, prêmio alemão concedido a escritores cuja língua materna não é o alemão, a Medalha Goethe em 2005, prêmio dado pelo Instituto Goethe a estrangeiros por seu mérito no sentido de difundir a língua e a cultura alemãs, objetivos principais do instituto ${ }^{2}$, entre outros. Recentemente, em 2016, foi-lhe concedido o Prêmio Kleist [Kleist-Preis]. Em entrevista à Deutschlandradio [Rádio alemã], a autora afirma que ter sido agraciada com tal prêmio lhe trouxe um sentimento de alegria ainda mais duradouro do que nos casos anteriores: desta vez, com o prêmio que é concedido a autores que se preocupam com a divulgação da literatura alemã para o mundo, a alegria é diferente, pois já não é um prêmio para uma estrangeira escrevendo na Alemanha. ${ }^{3}$

A obra de Tawada consiste principalmente em uma literatura ensaística, na qual elementos ficcionais se misturam às suas observações e teorias sobre o que é traduzir, o que é língua e de que forma nos relacionamos com os elementos linguísticos e culturais que nos formam e nos rodeiam. Por ser imigrante e dominar as duas línguas, suas considerações frequentemente abordam transformações, possibilidades e confusões metafísicas entre essas línguas e culturas. Conforme observou Hiltrud Arens (2007), seus escritos em alemão e em japonês examinam noções de cultura, tradição, linguagem, tradução, nação, gênero e identidade, e, como escritora de ambas as línguas, Tawada ocupa uma posição sem paralelos nas duas tradições literárias.

Arens acrescenta que Tawada utiliza a língua alemã de maneira complexa e trabalha em um esforço de negociação no sentido de transmitir uma herança cultural e linguística. Este esforço se daria por meio de atos simultâneos de memória e engajamento crítico com as tradições históricas e culturais japonesa e alemã, e sua escrita radicalizaria a instância do diálogo intercultural, do ponto de vista que o biliguismo em Tawada é explorado ainda de forma reversada, pois ela examina e negocia também como outsider com a língua materna.

Suas produções ficcionais se desenvolvem em um momento histórico marcado pela crescente experiência de globalização e por intensos movimentos de migração, o

\footnotetext{
${ }^{2}$ Ver em www.yokotawada.de.

${ }^{3}$ Ver a entrevista de Yoko Tawada à Deutschlandradio. Disponível em: http://www.deutschlandradiokultur.de/schriftstellerin-yoko-tawada-den-deutschen-japanerklaeren.970.de.html?dram:article id=360589. Acesso em 23 set. 2017.
} 
que parece delinear uma nova forma de contemporaneidade, na qual novas percepções da realidade e diferentes experiências de contato com o outro, o diferente, são geradas. A troca cultural, especialmente em grandes cidades como Berlim, Londres, Nova York, entre imigrantes, que buscam encontrar em terra estrangeira um novo lar, e a população local, que ganha a oportunidade de contato com novas ideias e com novas formas de pensar, têm se mostrado por um lado reconhecidamente enriquecedora e, por outro, fonte de controvérsias e acirradas manifestações contra e a favor deste movimento, discussões que se tornaram tema tanto nos lugares que são foco de movimentos migratórios como em todo o mundo, constituindo hoje um dos principais assuntos acerca do espaço contemporâneo.

A esse respeito, Salman Rushdie (1991) considera que tais movimentos tiveram por efeito a criação de um novo tipo de ser humano, definido mais por suas ideias e memórias do que por pertencimento a lugares ou pela posse de coisas materiais. Seriam pessoas que, por serem sempre definidas pelos outros, veem-se obrigadas a se definir pela própria alteridade. Ao cruzar fronteiras, o migrante adquire a capacidade de perceber a natureza ilusória da existência. Indivíduos que se movem, que cruzam fronteiras e que questionam a natureza dos espaços, das línguas e do próprio corpo são exatamente os personagens de Tawada. Da mesma forma, a autora traz conceitos de deslocamento e a percepção da existência de um entre-lugar, temas bastante perceptíveis em seus livros.

$\mathrm{Na}$ Alemanha, tem-se percebido o aumento considerável do número de imigrantes desde a metade do século XX, quando passou a acolher principalmente refugiados de origem alemã residentes em países do leste e sudeste europeu e também na década de sessenta, momento em que refugiados políticos e povos de todo o mundo passaram a afluir em grande escala. No campo da literatura surgem, a partir da década de setenta, os conceitos de literatura de migração [Migrationsliteratur] ou literatura intercultural [interkulturelle Literatur], que se referem à literatura de língua alemã escrita por autores pertencentes, originalmente, a outras línguas e que escolheram a língua alemã para desenvolver sua obra, voltada ao público leitor alemão. A esses grupos pertencem também os trabalhadores temporários [Gastarbeiter] ${ }^{4}$, que chegaram à Alemanha pós-guerra com o objetivo de trabalhar na reconstrução do país e depois regressar ao seu país, algo que para a maioria nunca aconteceu. Na atual Alemanha, este grupo configura hoje a terceira geração, na qual se encontram atualmente muitos expoentes da literatura alemã. Na Alemanha, escritores Feridun Zaimoglu, Emine Sevgi Özdamar, Franco Biondi, Rafik Schami, Jusuf Naoum ou Suleman Taufiq, entre outros, foram absorvidos e se tornaram parte da literatura nacional, ainda que, conforme críticas de alguns deles, tendam a ser vistos sempre como exóticos e deslocados. Nesse sentido, vêm surgindo inúmeras manifestações literárias de caráter teórico que abordam questões de escrita deslocada, de tradução e de interculturalidade. A este respeito, cabe mencionar um exemplo: em 2007, a Editora Reclam lançou um pequeno livro que reúne mais de uma dezena de autores que vivem e escrevem na Alemanha, entre os quais figura também Yoko Tawada, com o texto Eine leere Flasche [Uma garrafa vazia]. O livro é direcionado para o uso em sala de aula, como já se lê no título: Arbeitstexte für den Unterricht. Migrantenliteratur [Textos para a sala de aula. Literatura de migrantes], organizado Peter Müller e Jasmin Cicek.

\footnotetext{
${ }^{4}$ O termo Gastarbeiter significa trabalhador-convidado ou trabalhador-hóspede. Trata-se dos muitos trabalhadores que saíram principalmente do sul da Europa e da Turquia para trabalharem temporariamente da Alemanha a ser reconstruída após a Segunda Guerra Mundial.
} 
Eine leere Flasche é um ensaio particularmente interessante para fins didáticos porque nele são abordadas questões sobre pertencimento que ultrapassam os conceitos de fronteira ou nacionalidade para chegar às questões de gênero, sempre partindo do ponto de vista linguístico e das diferenças entre as culturas japonesa e alemã. No texto, Tawada revela a amplitude de suas discussões teóricas falando sobre como pode ser difícil para alguém ter de se definir como "homem" ou "mulher" e, por meio de uma narrativa carregada de lembranças da infância, a autora explica como são as expressões de autorreferenciação em língua japonesa: as meninas utilizam as palavras "atashi", "watashi" ou "atakushi" quando querem dizer "eu", dependendo de critérios sociais ou de idade, enquanto os meninos devem utilizar "boku" ou "ore". Para a autora, o problema reside no fato de alguém ter de se definir de acordo com tais critérios para, então, poder realizar a conexão entre as referências linguística e pessoal:

Era difícil para mim lidar com todas essas palavras que significam "eu". Eu não me sentia nem menino nem menina. Depois de adulta, uma pessoa pode se refugiar na palavra de gênero neutro "watashi", mas até lá as pessoas são obrigadas a serem moças ou rapazes. Como teria sido simples a minha infância se eu falasse outra língua - alemão por exemplo. Eu teria podido simplesmente falar sempre "eu". Para usar a palavra "eu" não é necessário sentir-se homem ou mulher" (TAWADA, 2002, p. 53-54).

A exemplo desse texto, o livro traz também outras discussões que dialogam com questões relacionadas à migração, língua e identidade e que fazem parte de um momento em que se busca valorizar as diferenças. Dividido em cinco capítulos, no livro figuram autores, na sua maioria desconhecidos do leitor brasileiro: o primeiro capítulo intitula-se A pátria perdida - perdido na pátria? e nele escrevem, entre outros, a Prêmio Nobel Herta Müller, Emine Sevgi Özdamar e o autor Saša Stanišić, atualmente reconhecido como autor do cânone literário alemão; o segundo capítulo, intitulado Vida na terra prometida - estranho entre estrangeiros?, traz 13 textos, entre eles, novamente um de Herta Müller e do autor Feridun Zaimoglu (1964), autor de origem turca (chegou com um ano de idade com sua família à Alemanha, em 1965); no terceiro capítulo, teremos o texto da autora aqui em questão, Yoko Tawada, com o texto Eine leere Flasche, já mencionado acima, em sintonia com o título do capítulo Questões em torno da identidade - estranho no próprio eu? em que também se tem, mais uma vez, um texto de Feridun Zaimoglu e um de outro autor de origem turca: Selim Özdogan (1971); no quarto capítulo, a temática gira em torno da língua, Falar Alemão - Ingressando na língua? e, neste, temos Mutterzunge [língua mãe], um texto bastante conhecido de Emine Sevgi Özdomar (1946), também autora de origem turca, e encontramos ainda um texto do brasileiro Zé do Rock ${ }^{6}$, "The omas \& the opas" [As avós e os avôs], além de

\footnotetext{
5 "Ich hatte Schwierigkeiten mit all diesen Wörtern, die »ich« bedeuten. Ich fühlte mich weder wie ein Mädchen noch wie ein Junge. Als Erwachsene kann man sich in das geschlechtsneutrale Wort »watashi« flüchten, aber bis man so weit ist, ist man gezwungen, ein Junge oder ein Mädchen zu sein. Wie einfach wäre meine Kindheit gewesen, wenn ich eine andere Sprache - zum Beispiel Deutsch - gesprochen hätte. Ich hätte dann einfach immer »ich« sagen können. Man muss sich weder weiblich noch männlich fühlen, um das Wort »ich« zu verwenden."

6 “Em 1995, o escritor Zé do Rock, porto-alegrense radicado em Munique, causou certa sensação no cenário editorial da Alemanha ao propor um divertido programa de reforma ortográfica da língua alemã, o "ultradoitsch". A proposta veio embalada nas memórias de sua viagem ao redor do mundo, publicadas em seu livro de estréia, fom winde ferfeelt (Editora Diá, Berlim). Em abril de 1997, o escritor esteve em São Paulo para realizar uma performance literária e para preparar o lançamento da versão brasileira desta
} 
outro texto de Yoko Tawada; o último capítulo, intitulado "Números - Fatos Fundamentos", traz textos informativos sobre a literatura tematizada no livro ${ }^{7}$.

\section{Literatura de migração}

Yoko Tawada costuma ser inserida no gênero chamado literatura de migração na Alemanha. A literatura alemã segue um modelo de classificações literárias no qual os gêneros recebem denominações de acordo com aspectos temáticos, como Exilliteratur, Frauenliteratur, Krimi- oder Horrorliteratur [literatura de exílio, literatura feminina, literatura de suspense ou de horror], conforme coloca Kurita (KURITA, 2015). O conceito de literatura de migração surgiu para designar a literatura produzida pelos migrantes que se estabeleciam em números cada mais significativos como trabalhadores após o chamado Milagre Econômico das décadas de 50 e 60. Neste contexto, surge primeiramente o termo Gastarbeiterliteratur como referência para a produção literária de tais trabalhadores [Gastarbeiter], que agora utilizavam a língua alemã para se expressar artisticamente. Grande parte dessa primeira onda de escritores vinha da Itália, da Turquia, do Oriente Médio e do Norte da África, e sua temática tratava de questões sociopolíticas relacionadas ao universo de trabalho, ao desprestígio e à marginalização do imigrante.

A partir do início dos anos 2000, porém, o conteúdo relacionado ao conceito de literatura de migração parece não mais corresponder à realidade da produção como um todo, dado o aumento do número de migrantes com motivos e origens diversas. Eles já não são necessariamente vinculados a um coletivo ou a um local de trabalho $\mathrm{e}$ reivindicam o reconhecimento de suas diferenças, bem como o reconhecimento de que o próprio termo carrega uma carga depreciativa. A nova geração de escritores provenientes de outros países, à qual Yoko Tawada pertence, é, portanto, bastante diferente, pois possui histórias mais individuais que não dialogam necessariamente com o peso dos problemas sociais, a questão dos trabalhadores estrangeiros na Alemanha. Ao ser questionada, em uma entrevista ${ }^{8}$, sobre sua opinião sobre o termo Literatura de Migração, a escritora explica como uma única designação não seria capaz de descrever sua obra: "Eu creio que esse termo, na verdade, não descreve o que eu faço. Apenas quem lê os meus livros sabe o que eu realmente faço. E é, de qualquer maneira, algo que não pode ser descrito em uma palavra"9 (TAWADA, 2009, p. 83).

E, ainda sobre o tema, explica como a posição de estrangeira ultrapassa qualquer categorização para fazer parte de sua própria condição de escritora: "Cada um deve

\footnotetext{
obra, o erói sem nem um agá, na qual, deixando de utilizar o português "errado", introduz o brasileiro "certo", ou seja, o "brazileis". Foi quando a revista Projekt o entrevistou - por fax - para que os leitores obtivessem, também, provas dessas duas novas "línguas"!". Citação extraída da apresentação da entrevista realizada por Lúcia Alt e Susana Kampff Lages para a Revista Projekt, da Abrapa. Disponível em: http://www.abrapa.org.br/p27-28s6-10.html . Acesso em 05 de jul. de 2019.

${ }^{7}$ Ver Peter Müller; Jasmin Cicek. Arbeitstexte für den Unterricht. Migrantenliteratur. Stuttgart: Phillip Reclam, 2007.

8 Ver a entrevista de Yoko Tawada à Heinrich Böll Stiftung: Disponível em http://heimatkunde.boell.de/sites/default/files/dossier_migrationsliteratur.pdf . Acesso em 23 set. 2017.

9 "Ich denke, diese Bezeichnungen beschreiben eigentlich nicht das, was ich mache. Was ich wirklich mache, wissen nur Leute, die meine Bücher lesen. Und das ist sowieso nicht mit einem Wort zu beschreiben."
} 
encontrar a sua estrangeiridade, nós precisamos ser estranhos, senão não haverá integração em uma sociedade em que vivem muitos e diferentes tipos de pessoas. Ser estrangeiro é uma arte"10 (TAWADA, 2009, p. 84). A autora demonstra que compreende a alteridade de maneira positiva, como uma experiência que deveria ser conscientemente buscada por todos.

Tal pensamento dialoga com a noção de que não é possível definir uma identidade a partir de um coletivo, pois grandes grupos já não representam indivíduos que cada vez mais buscam se construir a partir de suas experiências em vez do tradicional sentido de pertencimento a grupos ou nacionalidades. Para ela, é mesmo difícil definir-se como escritora japonesa ou alemã, e prefere sempre se designar como japonesa que vive na Alemanha, a partir de onde escreve. Desta forma, aparecem em sua produção, recorrentemente, personagens que transitam entre lugares e idiomas que desconstroem as certezas do que venha a ser ideia de país, de nacionalidade ou de cultura.

O romanista e comparatista alemão Ottmar Ette, ao analisar a obra de Yoko Tawada, especificamente no capítulo Insularien im aktuellen Globalisierungsschub [Insulários no movimento globalizador atual] do livro TransArea. Eine literarische Globalisierungsgeschichte [TransArea. Uma história literária da globalização], vê a produção da autora japonesa como um livro-ilha, um insulário dos continentes e das culturas, das línguas e dos jogos linguísticos, dos mundos-ilha e dos mundos insulares, mas que não estão isolados, pelo contrário, encontram-se justamente entre as culturas em um mundo em movimento ${ }^{11}$.

As relações entre os espaços e a subjetividade também são assuntos bastante abordados pela escritora. O espaço é explorado e questionado não apenas em sentido físico, mas também em sentido político e metafísico, pois atua na identidade de indivíduos perpassados por construções sociais, linguísticas e geopolíticas que, em verdade, contradizem a prenunciada formação de um mundo hiperintegrado e sem fronteiras. No ensaio Wolkenkarte [mapa das nuvens], Yoko Tawada expressa como o espaço geográfico se define pela língua e de que forma afeta a noção de pertencimento: "A senhora tem uma língua? Esta é uma pergunta importante. A senhora tem a língua necessária para pertencer a este lugar? Não, não tenho. Pois a minha língua não consegue pronunciar as palavras da mesma forma que a língua dos nativos ${ }^{12}$ (TAWADA, 2002, p. 52).

Em outro ensaio, Metamorphose der Personennamen [Metamorfose dos nomes], a autora joga com o som dos nomes e as modificações que neles ocorrem quando alguém deixa seu país para ingressar em outra cultura. Confundindo o nome pessoal com a própria essência daquele que o carrega, pois no momento em que um nome é tomado de algum lugar e preso a alguém, passa a ser tido quase como parte da própria personalidade, ela demonstra que todo o elemento humano é passível de transitar e de se modificar. Qualquer obliteração no reconhecimento da possibilidade desse movimento

\footnotetext{
10 “Jeder muss seine Fremdheit finden, entdecken, wir müssen fremd sein, sonst gibt es keine Integration in einer Gesellschaft, wo viele verschiedene Menschen leben. Fremd sein ist eine Kunst." Citação extraída da entrevista mencionada acima.

${ }^{11}$ Ver Ottmar Ette, TransArea Eine literarische Globalisierungsgeschichte, Berlin/Boston: de Gruyter, 2012, p. 300.

12 "Haben Sie eine Zunge? Das ist eine wichtige Frage. Haben Sie die Zunge, die man braucht, um hierher zu gehören? Nein, habe ich nicht. Denn meine Zunge kann die Wörter nicht so aussprechen wie die Zunge der Einheimischen."
} 
torna-se redutora e perpetua um pensamento construído ideologicamente, que apenas tolhe a liberdade de criação:

Com isso, os dois conceitos - a integração e a origem - não constituem uma oposição, mas são duas faces de uma ideologia. [...] Eu também sempre procuro novos lugares. Quando os leitores começam a acreditar que podem encontrar em meus textos o olhar japonês sobre a Europa, eu me sinto como que empurrada e encarcerada em uma cela chamada origem ${ }^{13}$ (TAWADA, 2007, p. 93-101).

Tawada considera o transitar, o viajar e o migrar elementos constituintes do subjetivo, assim como da literatura, pois o material literário nunca esteve somente ligado a uma cultura ou nacionalidade, mas se constitui de todas as fontes culturais intrínsecas à sua escritura; e, depois de pronto, passa a ser também elemento formador quando se vê livre para transitar através das fronteiras e ganhar novas leituras, traduções e interpretações, como seria o clássico exemplo de Shakespeare, que trouxe muitas de suas peças da tradição italiana, que por sua vez bebia sempre em fontes asiáticas. No ensaio Der Apfel und die Nase [A maçã e o nariz] ela escreve:

Na literatura clássica do leste europeu, a flor, juntamente com o pássaro, o vento e a lua, é um dos quatro temas mais importantes da poesia, mas como eu fui bem mais influenciada por "O Nariz" de Nikolai Gógol do que por "

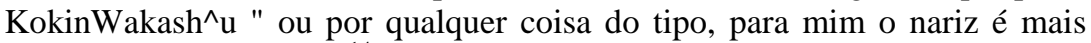
importante do que a flor. ${ }^{14}$ (TAWADA, 2002, p.16-17)

Toda a instituição da literatura moderna está fundamentada em traduções entre línguas nacionais, e todos os autores de uma forma ou de outra se inspiram ou se inspiraram em muitas literaturas de diferentes origens, cada uma com suas respectivas filogenias. Às vezes, a influência pode ser identificada como motivos, estruturas, temas; em outros momentos, a influência é, literalmente, um in-fluxo, o uso direto de palavras ou locuções transpostas a partir de um elemento estrangeiro, e a posse de um idioma e a integração em uma comunidade monolinguística já foi questionada por alguns escritores como Conrad, Joyce, Nabokov e Beckett (SUGA, 2007). Nesse sentido, Tawada entende o uso das línguas estrangeiras como meio tanto de interação diária como de criação artística, de modo que apenas é possível escrever fora da língua materna, em constante e inevitável produção literária exofônica, termo que abordaremos a seguir.

\section{Exofonia}

\footnotetext{
13 "Dabei bilden die beiden Begriffe, die Integration und die Herkunft, keine Gegensätze, sondern sie sind zwei Gesichter einer Ideologie. (...) Auch ich suche stets nach neuen Orten. Wenn die Leser anfangen zu glauben, in meinen Texten den japanischen Blick auf Europa finden zu können, fühle ich mich wie zurückgestoßen und eingesperrt in einer Zelle namens Herkunft."

14 "In der klassischen ostasiatischen Literatur gehört die Blume neben dem Vogel, dem Wind und dem Mond zu den vier wichtigsten Motiven der Dichtung, aber da ich eher von Nikolai Gogols <Nase> beeinflusst bin als vom <"Kokinwakash^u> oder Ähnlichem, ist die Nase für mich wichtiger als die Blume."
} 
O termo "exofonia" descreve o fenômeno no qual um escritor adota uma linguagem literária diferente da sua língua materna, complementando-a ou a substituindo totalmente como veículo de expressão literária. A segunda língua é tipicamente adotada na fase adulta; escritores exofônicos não são bilíngues no sentido de terem se criado falando as duas línguas e, de fato, não necessariamente possuem a fluência associada ao termo "bilinguismo" (WRIGHT, 2013). Yoko Tawada é uma escritora tipicamente exofônica, como ela própria costuma se definir. Em seu livro intitulado "Exofonia", publicado no Japão em 2003, a autora traz sua visão pessoal sobre tal condição e explica que as línguas em si não são o principal, mas sim o espaço criado entre elas. Um escritor deve se colocar como observador em relação às línguas, tanto à materna quanto à adotada, para que sejam desconstruídas e reconstruídas "em experimentos aventurescos que assumiriam a exofonia em vez de tentar buscar a eufonia, fluxo suave e assimilado de tons harmoniosos" (TACHIBANA, 2007, p. 153). Em Ekusophonii: bogo no soto e deru tabi [exofonia - uma viagem para fora da língua materna], ela escreve:

\begin{abstract}
Mover-se para fora do círculo da língua materna é como se entregar a uma música estranha. [...] Se alguém vive dentro de uma crença inquestionável na "naturalidade" da língua nativa [bogo], nenhuma interação verdadeira com essa língua pode se desenvolver; [sem tal questionamento] não haveria literatura contemporânea. Assim, deslocar-se para fora da língua nativa não é, para a literatura, uma situação especial, é simplesmente o extremo da situação normal (TAWADA, 2003, p.77). ${ }^{15}$
\end{abstract}

Tachibana (2007, p. 154) explica que Tawada tenta produzir exofonia nas duas línguas, e que foca a atenção no japonês quando pretende desconstruir o que chama de "conceito ultranacionalista de bela língua japonesa". Lembrando que a língua, a priori, não existe, observa que a criação do japonês moderno como língua nacional remonta à era Meiji (1868-1912), quando o Japão, confrontado pela pressão ocidental, tenta imitar e absorver sua cultura como forma de resistência, tomando como exemplo principalmente o modelo da Prússia. No conto $M a$ und $M u$ [Ma e Mu], Tawada faz uma revisão crítica sobre o histórico japonês de imitar outras culturas em vez de se deixar criar livremente em seu espaço cultural:

Ao longo da história, o Japão, em vez de construir uma utopia, sempre tomou algum outro país como exemplo, tentando imitar o país escolhido e superá-lo. O imitador não é muito criativo, e de modo algum original. É como a segunda infusão de um chá. Mas a segunda infusão tem uma vantagem que agrada especialmente aos políticos covardes e irresponsáveis: pode-se observar se aquele que bebe da primeira infusão primeiro se queima. (...) $\mathrm{Na}$ Modernidade, os exemplos do Japão foram a França, a Inglaterra, a Prússia e os Estados Unidos. O hábito de tomar o exemplo de países realmente existentes em vez de desenvolver uma utopia não mudou. Isso quer dizer que o futuro nunca foi uma questão de distância temporal, mas geográfica. ${ }^{16}$ (TAWADA, 2007, p. 112-113)

\footnotetext{
${ }^{15}$ A tradução do texto do japonês para o português foi realizada com o auxílio do Prof. Dr. Andrei dos Santos Cunha, professor do Setor de Japonês, da Universidade Federal do Rio Grande do Sul.

16، Japan hat sich in der Geschichte immer wieder ein anderes Land als Vorbild ausgesucht, anstatt sich eine Utopie auszumalen. Man versuchte dann, das ausgesuchte Land nachzuahmen und es zu überholen. Der Nachahmer ist nicht besonders kreativ, auf gar keinen Fall originell. Man bezeichnet ihn als den zweiten Aufguss vom Tee. Aber das zweite Aufguss hat einen Vorteil, der den feigen und
} 
Ainda segundo a análise de Tachibana, que busca articular a resistência de Tawada à ideologia nacionalista, desenvolvida em torno da língua desde a era Meiji, a escritora problematiza esta ideologia e o etnocentrismo japonês na era moderna através da questão linguística. Revisando a criação de um padrão nesse sentido, lembra que quando os líderes japoneses decidiram aceitar as influências ocidentais após a Restauração Meiji, a situação linguística era bastante confusa no Japão, pois o povo utilizava diferentes idiomas e dialetos de acordo com a localidade e com a classe social. Em resposta aos esforços para tornar-se uma nação competitiva em relação ao ocidente, os governantes deveriam criar rapidamente uma unidade histórica, cultural e linguística, ainda que de maneira forçada. Entre outras medidas, criou-se uma língua padrão, escrita e falada, para toda a população em consonância com o conceito de língua nacional que fundamentava a construção do Japão como estado nacional moderno.

Tawada trata de entrecruzamentos políticos e linguísticos em diversos contextos históricos, utilizando sempre muitos exemplos sobre a política do Japão. No conto Bioskoop der Nacht [Cinema noturno], a autora tece suas considerações em uma ficção repleta de memórias oníricas, e mostra, mais uma vez, como a política pode agir de maneira externa à língua e desconsiderar os povos em si, o que é uma situação incoerente. Ela explica que na época do Apartheid, os políticos sul-africanos haviam declarado os japoneses como brancos para restaurar as relações econômicas entre os dois países e, com ironia e um toque de humor, lembra de uma cena que viveu na infância:

\begin{abstract}
Eu não sabia muito sobre a África do Sul. Mas o que me veio imediatamente à memória foi uma foto que eu havia visto quando criança em um livro da escola. A foto mostrava as duas portas de um banheiro público. Em uma porta estava "Para brancos", e, na outra, "Para outros, exceto japoneses". Nós não podíamos ir a nenhum dos toilettes. Não tive coragem de perguntar ao professor de que forma seria do interesse do Apartheid deixar nossas necessidades do lado de fora ${ }^{17}$ (TAWADA, 2002, p. 67-68).
\end{abstract}

Se toda uma reflexão histórica subjaz ao questionamento sobre o que é uma língua e em que medida ela é natural e constituinte da comunicação humana ao mesmo tempo em que pode ser utilizada como instrumento de imposição e inclusão/exclusão, quando Tawada trata da língua alemã, adota uma postura de ingenuidade e admiração pelos efeitos metafísicos que percebe ao utilizá-la com a liberdade de um aprendiz e também com a descoberta da sensação de ser vista como elemento estrangeiro, portanto, deslocado, na visão do outro. No limite, ao integrar sua visão de que um indivíduo é a própria língua e que exatamente nessa fusão indivíduo/língua pode ser alijado da condição humana enquanto não pertencente a um grupo de indivíduos/línguas diferente,

antwortungslosen Politikern besonders gut gefällt. Man kann nämlich beobachten, ob derjenige, der vom ersten Aufguss trinkt, sich daran verbrennt. (...) In der Moderne waren die Vorbilder Japans Frankreich, England, Preußen und die USA. Die Gewonheit, ein Vorbild als real existierenden Länder auszusuchen, anstatt eine eigene Utopie zu entwickeln, änderte sich nicht. Das heißt, die Zukunft lag nie in einer zeitlichen, sondern immer in einer geographischen Ferne.”

17 "Über Südafrika wusste ich nicht viel. Was mir aber sofort in den Sinn kam, war ein Foto, das ich als Kind im Schulbuch gesehen hatte. Das Foto zeigte zwei Türen von öffentlichen Toiletten. Auf einer Tür stand »Für die Weißen« und auf der anderen »Für die anderen außer Japanern«. Wir dürften also weder in die eine noch in die andere Toilette gehen. Ich hatte nicht den Mut, den Lehrer zu fragen, warum es im Interesse der Apartheid sei, unsere Notdurft auszusperren.” 
assume uma perspectiva kafkiana, quando usa a parábola de uma metamorfose para expor o que julga ser o fundamento da existência em um ensaio como "Zungen-Tanz" [Dança da Língua]:

Eu era uma língua. Saí de casa assim, nua, rosa e insuportavelmente úmida. Era fácil causar admiração nas pessoas na rua, no entanto ninguém queria me tocar. Mulheres de plástico sem órgãos genitais estavam expostas nas vitrines. Os preços das etiquetas haviam sido riscados com lápis vermelho. Cidadãos prudentes tocam apenas em línguas bem embaladas em folhas plásticas $^{18}$ (TAWADA, 2002, p. 9-10).

Tawada questiona o que é língua materna e em que medida ela poderia se diferenciar de uma segunda língua, uma língua estrangeira. Na verdade, a língua que se aprende na infância seria tão estrangeira quanto qualquer outra, pois a criança tem de se confrontar com signos cujo significados são dados, ou seja, ela tem de aprender a lidar com uma língua pronta e conhecer seus significados da mesma forma como se aprende uma língua estrangeira. Em entrevista à Ortrud Gutjahr, a autora conta como, quando criança, via as palavras como se fossem pedras que podiam ser atiradas nas pessoas e lembra:

Sempre que eu atirava nas pessoas uma palavra cujo significado ainda não conhecia bem, podia ver que surgiam ondas. E essas palavras que eu atirava eram da minha própria língua materna, o japonês - que, na época, ainda era estrangeira para mim. Nós aprendemos a língua materna como primeira língua estrangeira ${ }^{19}$ (TAWADA, 2012, p. 41).

Da mesma maneira que já se aprende a primeira língua como estrangeira, tornase complicado imaginar que alguém possa exercer algum domínio sobre qualquer língua. Os indivíduos, quando aprendem a língua, antes de dominá-la, integram-se a ela. E assim como uma língua não é passível de pertencimento, ela também não tem condições de representar uma nação ou oferecer aos indivíduos uma estabilidade que não possui. Por isso, Tawada propõe a existência espaço entre-linguístico como pátria, e trata da integração fundamental entre a subjetividade humana e os elementos culturais dos quais a língua se revela como vetor essencial, elementos que não podem ser limitados, medidos ou controlados por fronteiras. Em sua vivência na Alemanha, Tawada observa a postura dos alemães com relação ao tema e, no conto Die Ohrenzeugin [Testemunha auditiva] escreve:

A maioria dos alemães não afirmaria que o alemão não pode ser escrito pelos
outros. Mas, indiretamente, volta e meia dão a entender que a língua tem de
ser uma propriedade. Eles dizem, por exemplo, que não se pode dominar uma
língua estrangeira tão bem quanto a língua materna. Logo se percebe que o
importante para eles é o domínio. Na minha opinião, dominar uma língua é

18 "Ich war eine Zunge. Ich ging so aus dem Haus hinaus, nackt, rosa und unerträglich feucht. Es war einfach, Menschen auf der Straße zu entzücken, keiner wollte mich jedoch anfassen. Im Schaufenster standen Plastikfrauen ohne Geschlechtsorgane. Die Preise auf den Schildern waren mit einem Rotstift durchgestrichen. Vorsichtige Bürger berüren nur die in Plastikfolien eingepackten Zungen."

19 "Immer wenn ich ein Wort in die Menschen hineingeworfen habe, dessen Bedeutung ich noch gar nicht genau kannte, konnte ich doch sehen, dass es Wellen gibt. Und diese geworfenen Wörter waren aus meiner Muttersprache Japanisch - die war damals noch Fremd. Wir lernen als erste Fremdsprache die Mutterspache." 
algo supérfluo. Ou se tem um relacionamento com ela ou não se tem nada. Outros dizem que só é possível expressar sentimentos de forma autêntica em língua materna, em língua estrangeira, mente-se involuntariamente. A busca pelo sentimento autêntico os deixa perturbados quando veem sua própria língua como idioma estrangeiro. Há outros ainda que afirmam que em uma língua estrangeira a infância está ausente. Mas em nenhum outro lugar eu encontrei tanta infância quanto em alemão ${ }^{20}$ (TAWADA, 2002, p. 110).

Yoko Tawada entende que a capacidade de pensar e escrever em uma língua diferente da materna exerce grande influência no que é pensado e escrito. Por isso a diferença entre o que um falante de uma determinada língua pensa e compreende e as suas possibilidades de se expressar em uma língua pertencente a outra cultura é um de seus principais temas. Neste campo, a tradução interlingual e a tradução cultural se revelam como pontos cruciais de suas reflexões. Segundo Ulfat (2011), a autora propõe que por meio da tradução de um universo de pensamento próprio se leia uma forma de pensar constituída pelo que se assimila da língua e da cultura maternas para outra língua, e então esse universo de pensamento se despe e se liberta de seus ornamentos. E apenas assim, nu, ele pode verdadeiramente se revelar e o falante, finalmente utilizar sua língua de maneira emancipada.

\section{Considerações finais}

O trabalho de Yoko Tawada se ocupa principalmente das questões da língua e da sua importância como elemento formador do indivíduo e dos coletivos aos quais pertence, considerações que partem do ponto de vista de alguém que deixou a terra natal para viver em outro país e que questiona justamente o que é ser estrangeiro ou, antes, se existe realmente a possibilidade de definir-se algo ou alguém como estrangeiro. Ao mesmo tempo em que é categorizada na Alemanha como escritora da "literatura de migração", faz questão de demonstrar o quanto esse termo é insuficiente para descrever sua obra. No livro Exofonia, ela salienta que não pertence a nenhuma nacionalidade, pois vive em um entre-lugar, o espaço que se forma entre as línguas.

A proposição de um espaço entre-linguístico como pátria, ou como lar, revela sua crença na integração fundamental da subjetividade humana com os elementos culturais, dos quais a língua se revela como vetor essencial, que a formam e que não podem ser limitados, medidos ou controlados por fronteiras. Sua literatura, não raro, reveste-se de teor irônico e metafórico com o objetivo de desnudar sistemas artificialmente impostos por diferentes razões históricas ou políticas que apenas

\footnotetext{
20 "In Deutschland würden die meisten Menschen nicht behaupten, dass die deutsche Sprache von anderen nicht geschrieben werden darf. Aber indirekt geben sie einem immer wieder zu verstehen, dass die Sprache ein Besitztum sein muss. Sie sagen zum Beispiel, dass man eine Fremdsprache nie so gut beherrschen könne wie die Muttersprache. Man bemerkt sofort, dass das Wichtigste für sie die Beherrschung ist. Meiner Meinung nach ist es überflüssig, eine Sprache zu beherrschen. Entweder hat man eine Beziehung zu ihr oder man hat keine. Andere sagen, nur in der Muttersprache könne man authentisch seine Gefühle ausdrücken, in einer Fremdsprache lüge man unwillkürlich. Sie fühlen sich bei ihrer Suche nach dem authentischen Gefühl gestört, wenn sie ihre Sprache auf fremden Zungen sehen. Es gibt auch Menschen, die behaupten, in einer Fremdsprache ist die Kindheit abwesend. Aber ich fand nirgendwo so viel Kindheit wie in der deutschen Sprache."
} 
deformam e reduzem a representação do indivíduo. Conhecer a própria língua é sair dela, assim como se conhecer é reconhecer a alteridade.

A literatura contemporânea não pode deixar de revelar os traços culturais a que está vinculada e os movimentos históricos e teóricos a que pertencem. Yoko Tawada, assim como outros escritores com histórico de migração, contribui para 0 desenvolvimento de uma literatura com características multiculturais e repleta de reflexões sobre conceitos como espaço, língua e pertencimento, temáticas intimamente relacionadas com os estudos de língua e literatura.

\section{REFERÊNCIAS}

ARENS, Hiltrud. Das kurze Leuchten unter dem Tor oder auf dem Weg zur geträumten Sprache: Poetological Reflections in Works by Yoko Tawada. In: SLAYMAKER, Doug (Org). Yoko Tawada: voices from everywhere. Lanham, Lexington Books, 2007, p.59-76.

ETTE, Ottmar. TransArea. Eine literarische Globalisierungsgeschichte. Berlin/Boston: de Gruyter, 2012.

TAWADA, Yoko. In meinen Poetikvorlesungen werde ich viel über das Wasser sprechen, und der Tsunami kommt auch vor. In: GUTJAHR, Ortrud (Org.) Fremde Wasser. Tübingen: Claudia Gehrke, 2012, p. 17-45.

KURITA, Yukari. Migrantenliteratur In: Deutschland: Eine Untersuchung zu Sprache und Gedanken von Yoko Tawada. Tóquio, Universidade Gakushuin, 2015, p.75-94.

LACKA, Danuta. Trans-gender, Trans-bordering, Translations in Yoko's Narrative. Tóquio, 2009. Disponível em: http://repository.dl.itc.utokyo.ac.jp/dspace/bitstream/2261/53374/1/lis00717.pdf . Acesso em: 23 out. 2018.

MÜLLER, Stefan; CICEK, Jasmin. Arbeitstexte für den Unterricht. Migrantenliteratur. Stuttgart: Phillip Reclam, 2007.

RUSHDIE, Salman. Imaginary Homelands: Essays and Criticism, 1981-1991. Londres, Granta Books, 1991.

SLAYMAKER, Doug. Introduction Yōko Tawada: Voices from Everywhere In: (Org). Yoko Tawada: voices from everywhere. Lanham: Lexington

Books, 2007, p. 1-12

SUGA, Keijirō. Translation, Exophony, Omniphony. In: SLAYMAKER, Doug (Org). Yoko Tawada: voices from everywhere. Lanham: Lexington Books, 2007, p. 21-34. 
TACHIBANA, Reiko. Tawada Yōko's Quest for Exophony: Japan and Germany. In: SLAYMAKER, Doug (Org). Yoko Tawada: voices from everywhere. Lanham: Lexington Books, 2007, p. 153-168.

TAWADA, Yoko. Bogo no soto e deru tabi Tóquio: Iwanami, 2003. Título em japonês: エクソフォニー——母語の外へ出る旅.

TAWADA, Yoko. Der Apfel und die Nase. In: . Überseezungen. Tübingen: Ed. Cláudia Gehrke, 2002, p.15-17.

TAWADA, Yoko. Die Ohrenzeugin. In: Überseezungen. Tübingen: Ed. Cláudia Gehrke, 2002, p. 95-114.

TAWADA, Yoko. Eine leere Flasche. In: Überseezungen. Tübingen: Ed. Cláudia Gehrke, 2002, p. 53-57.

TAWADA, Yoko. Fremd sein ist eine Kunst. Heinrich Böll Stiftung, Berlim, p. 81-85, mar 2009. Disponível em: http://heimatkunde.boell.de/sites/default/files/dossier_migrationsliteratur.pdf. Acesso em: 24 out. 2017

TAWADA, Yoko. Ma und Mu. In: Sprachpolizei und Spielpolyglotte. Tübingen: Ed. Cláudia Gehrke, 2007, p. 110-121.

TAWADA, Yoko. Metamorphosen der Personennamen. In: und Spielpolyglotte. Tübingen: Ed. Cláudia Gehrke, 2007, p. 93-102. Sprachpolizei

TAWADA, Yoko. Wolkenkarte. In: Überseezungen. Tübingen: Ed. Cláudia Gehrke, 2002, p. 51-52.

TAWADA, Yoko. Zungen-tanz. In: Überseezungen. Tübingen: Ed. Cláudia Gehrke, 2002, p. 9-14.

ULFAT, Jasamin. Eine Sprache zwischen Japanisch und Deutsch - Yoko Tawadas Botin in den Überseezungen. Berlim, Centro Nipo-germânico de Berlim (JDZB), 201, p. 204-214.

WRIGHT, Chantal. Yoko Tawada's Portrait of a tongue. Universidade de Ottawa, 2013.

YILDIZ, Yasemin. Tawada's Multilingual Moves: Toward a Transnational Imaginary. In: SLAYMAKER, Doug (Org). Yoko Tawada: voices from everywhere. Lanham: Lexington Books, 2013, p. 77-89. 